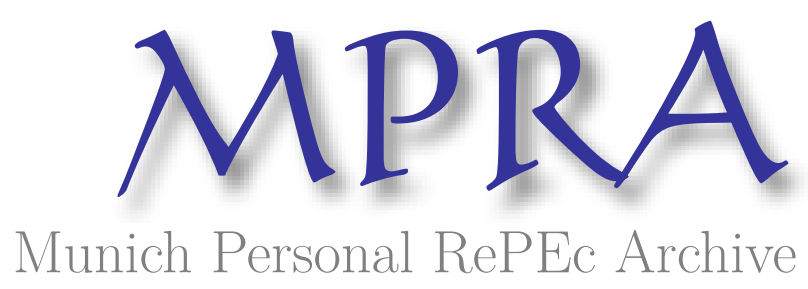

\title{
Implementation of the Walrasian Correspondence without Continuous, Convex, and Ordered Preferences
}

\author{
Tian, Guoqiang
}

11 March 1991

Online at https://mpra.ub.uni-muenchen.de/41298/

MPRA Paper No. 41298, posted 19 Sep 2012 11:38 UTC 


\title{
Implementation of the Walrasian correspondence without continuous, convex, and ordered preferences
}

\author{
Guog̣iang Tian \\ Department of Exonomics, Texas A \& M University, College Station, TX 77843, USA
}

Recived March 11. 1991 / Actepted November 6. 1991

\begin{abstract}
This paper consideres the problem of designing "better" mechanisms whose Nash allocations coineide with constrained Walrasian allocations for nonneoclassical economies under the minimal possible assumptions. We show that no assumprions on preferences are needed for leasible and continuous implementation of the constrained Walrasian correspondence. Further, under the monotonicity assumption, we present a mechanism that is completely leasible and continuous. Hence, no eontinuity and convexity assumptions on preferences are required. and preferences may be nontotal or nontransitive. Thus, this paper gives a somewhat positive answer to the question raised in the literature by showing that, even for non-neodassical economits, there are "incentive-compatible", "privacy preserving". and "well-behaved" mechanisms which yield Paretomefficient and individually rational allocations at Nash equilibria.
\end{abstract}

\section{Introduction}

In the early literature (e.g., Bergson [2], Lange [17], Debreu [3]), much of the traditional welfare economics lakes an economic mechanism (e,g., the competitive mechanism or monopoly mechanism) as given and investigates the properties (e.g. Pareto-efficiency) of its performance correspondence. Subsequently, the ren verse problem has come under consideration: instead of regat ding the mechanisms as given and seeking a class of environments for which they work, one seeks mechanisms that will implement some social goals (social choice correspondences) for a given class of environments without destroying participants" incentives, and these mechanisms will have some desirable properties. In particular, for a set of "non-neoclassical" economic environments, steh as those with non-convexities,

- I wish to thank J. S. Chipman, J. Jordan, M. Richter, H. Weinberger, the editor, and two anonymous referees for useful comments and suggestions. I am particularly thankful to L. Hurwicz who stimulated my interest in this problem and provided detalled comments and suggestions. 


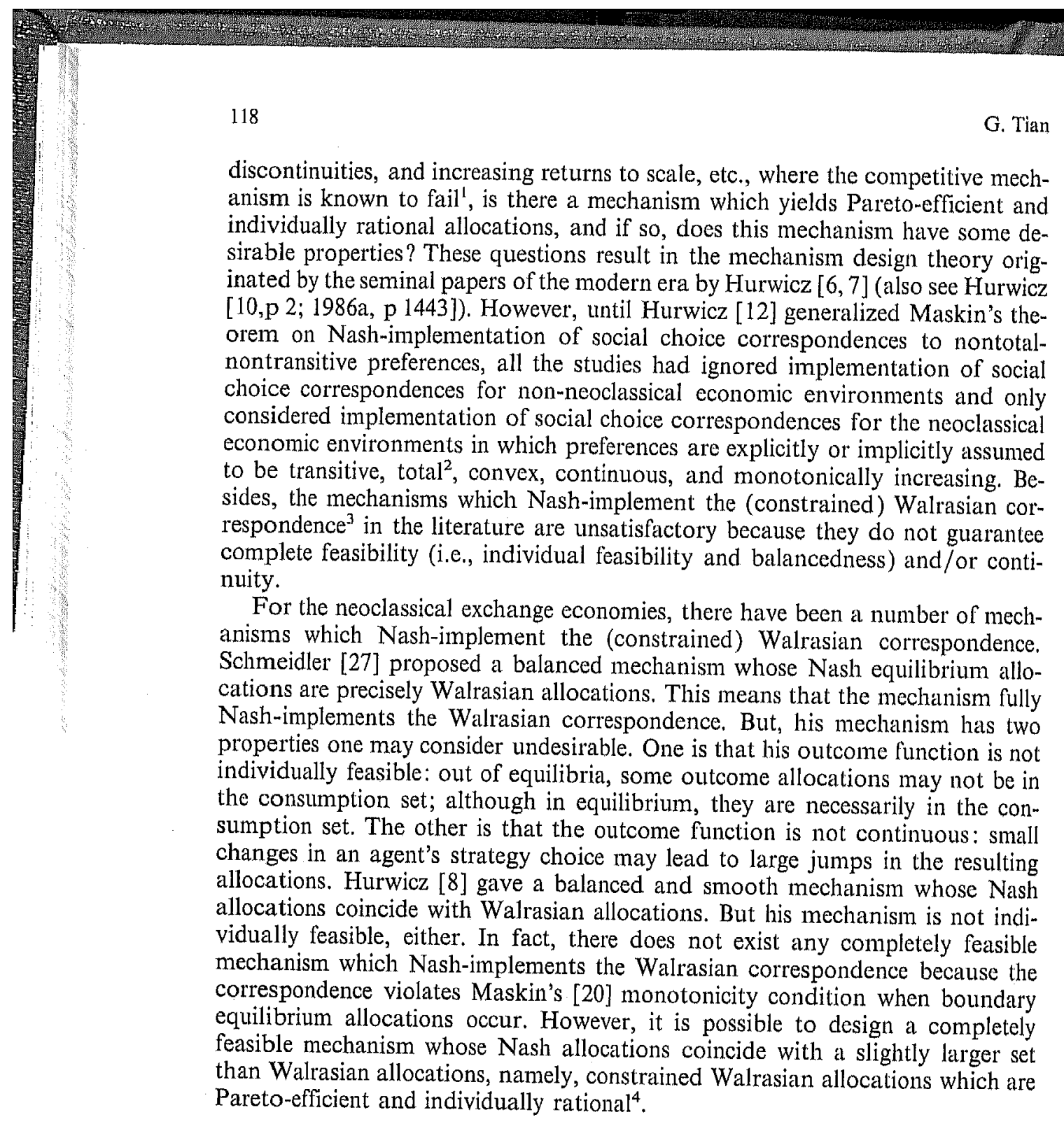

1 Even for the neoclassical economic environments, the competitive (Walrasian) mechanism may fail when the number of agents in an economy is small. This is because, in this case, agents are not likely to be "price takers". Consequently, the efficiency of outcomes may not follow from the competitive mechanism. Thus, the Walrasian mechanism fails to yield Pareto-efficient allocations in the case of a small number of agents. In fact, this is one of the reasons why, even for the neoclassical economies, economists want to seek some alternative mechanisms which yield Pareto-efficient allocations.

${ }_{2}$ A preference relation $R$ is said to be total if for any $x$ and $y, x \neq y$ implies $x R y$ or $y R x$. ${ }^{3}$ It is important to distinguish the competitive mechanism (the Walrasian mechanism) from the Walrasian correspondence (cf. Hurwicz [13, p 284]). The former is a market economic mechanism, but the latter is a performance correspondence which consists of allocations which can be supported (obtained) by the competitive mechanism and, in fact, can be implemented by non-Walrasian mechanisms, e.g., by the mechanisms presented in the paper.

4 Note that even though Walrasian equilibria do not exist (so that the competitive mechanism still exist (cf. Example 1 below). 
Economic motivation behind consideration of the constrained Walrasian correspondence is, of course, that considering implementation of the constrained Walrasian correspondence does not lose much generality, compared to implementing any other social choice correspondence which guarantees Pareto-efficiency and individual rationality. Indeed, as Hurwicz et al. (1984) pointed out, a slightly modified varsion of Theorem 1 and 2 of Hurwicz [9] states that for any mechanism, if all of its Nash allocations for a given environment are Paretoefficient and individually rational, then every constrained Walrasian allocation is a Nash allocation, and every interior Nash allocation is a constrained Walrasian allocation. Thus, considering implementation of the constrained Walrasian correspondence at most loses some possible boundary Pareto-efficient and individually rational allocations.

Hurwicz et al. [14] then proposed a completely feasible mechanism that Nashimplements the constrained Walrasian correspondence. Their mechanism, however, is discontinuous. Postlewaite and Wettstein [25] gave a continuous and feasible (i.e., individually feasible and weakly balanced) mechanism which Nashimplements the constrained Walrasian correspondence. Their mechanism, however, is not balanced and the continuity of utility functions is a critical assumption for their mechanism. Balancedness is highly desirable if we are to seriously consider accepting the mechanisms. For the motivation behind designing balanced mechanisms, see Tian $[34,36]$.

A similar situation prevailed with regard to Nash-implementation of the Lindahl correspondence for the neoclassical public goods economies (see, e.g., mechanisms in Groves and Ledyard [4], Hurwicz [8], Walker [40], Groves and Ledyard. [5], Tian [33]) until Tian [34,36] and Tian and $\mathrm{Li} \mathrm{[38]} \mathrm{recently} \mathrm{gave} \mathrm{completely}$ feasible and continuous mechanisms which fully Nash-implement the Lindahl correspondence, and further have message spaces of minimal dimension.

Thus all mechanisms mentioned above only work with the neoclassical preferences which guarantee the existence of Walrasian allocations. There are no answers to the questions (which were stated in the beginning of the paper) whether or not there exist mechanisms which yield Pareto and individually rational allocations at Nash equilibria for the non-neoclassical economies, and if so, whether or not they are continuous and feasible or further if they are continuous, individually feasible, and balanced (not merely weakly balanced). This paper gives somewhat positive answers to these questions by implementing the constrained Walrasian correspondence. It will be noted below that only monotonicity of preferences is assumed in our completely feasible and continuous mechanism and thus no continuity and convexity assumptions on preferences are needed, and further, preferences may be nontotal or nontransitive. In fact, the only assumption, monotonicity, we impose on preferences cannot be dispensed with for balanced implementation (see Remark 7 below). Moreover, the monotonicity assumption can be dropped if we only want to have a weakly balanced, individually feasible, and continuous mechanism. Thus we can have a feasible and continuous mechanism whose Nash allocations coincide with the constrained Walrasian correspondence without imposing any assumptions on preferences. These results show that, even for non-neoclassical economies, there are "incentive-compatible", "privacy preserving", and "well-behaved" mechanisms whose Nash allocations, provided they exist, yield Pareto-efficient and individually rational allocations. These also show that no assumptions on preferences are needed for implementation of the constrained Walrasian correspondence for the class of economies 
on which it is nonempty-valued. Thus, our mechanisms work at least for the following two cases where the competitive mechanism may fail. One is the case where the number of agents is small. The second case is that constrained Walrasian equilibria exist even though Walrasian equilibria may not exist. So our results add some new dimensions to our understanding of the mechanism design theory.

As can be seen in many cases, preferences of an agent are nontransitivenontotal. For instance, as Hurwicz [12] pointed out, this is the case when the society whose goals are to be implemented consists of groups whose choices are defined by voting procedures. Also, Mosteller and Nogee [22] noted that in experiments to test transitivity of preferences, one could always find instances in which this postulate was violated. This enables economists to study behavior of agents with nontotal-nontransitive preferences. Many studies in the literature show the existence of maximum elements of preferences and the existence of Walrasian equilibrium such as those in Schmeidler [26], Sonnenschein [29], MasColell [18], Shafer and Sonnenschein [28], and Tian [37], among others.

The plan of this paper is as follows. Section 2 gives notation and definitions used in the mechanism design literature. Section 3 presents a mechanism which is completely feasible and continuous and shows equivalence of Nash allocations of the mechanism and the constrained Walrasian allocations when monotonicity of preferences is assumed. Section 4 drops the monotonicity assumption and gives a feasible and continuous mechanism which implements the constrained Walrasian correspondence without imposing any conditions on preferences. Finally, some concluding remarks on possible extensions of our results are given in Sect. 5.

\section{Notation and definitions}

\subsection{Economic environments}

In the economy under consideration, there are $n\left(n \geqq 3\right.$ agents $\left.{ }^{5}\right)$ who consume $L$ private goods. Denote by $N=\{1,2, \ldots, n\}$ the set of agents. Each agent's characteristic is denoted by $e_{i}=\left(w_{i}, P_{t}\right)$, where $w_{i} \in \mathbb{R}_{+}^{L} \backslash\{0\}$ is the initial endowment of the agent and $P_{i}$ is the strict (irreflexive) preference defined on $\mathbb{R}_{+}^{L}$ which may be nontotal or nontransitive ${ }^{6}$.

An economy is the full vector $e=\left(e_{1}, \ldots, e_{n}\right)$ and the set of all such economies is denoted by $E$.

\footnotetext{
5 This is a necessary condition for the balanced and continuous implementation. Kwan and Nakamura [16] proved that there are no balanced and continuous mechanisms which implement the (constrained) Walrasian correspondence for two-agent economies.

${ }^{6}$ If we define the binary relation $P_{i}^{*}$ by a $P_{i}^{*} b$ if and only if $\neg b P_{i} a$ where $\neg$ stands for "it is not the case that", then $P_{i}^{*}$ is the weak (reflexive) preference and is called the "canonical conjugate' of $P_{1}$ (see $\mathrm{Kim}$ and Richter [15]). If concepts used in this paper such as Nash equilibrium and the constrained Walrasian allocations are interpreted in terms of the $P^{*}$, then the results obtained in this paper for $P_{i}$ are, inparticular, valid for the $P_{l}^{*}$.
} 


\subsection{The constrained Walrasian allocations}

An allocation $x^{*}=\left(x_{1}^{*}, x_{2}^{*}, \ldots, x_{n}^{*}\right) \in \mathbb{R}_{+}^{n L}$ is a constrained Walrasian allocation for an economy $e$ if there is a price vector $p^{*} \in \mathbb{R}_{+}^{L}$ such that

(1) $p^{*} \cdot x_{i}^{*} \leqq p^{*} \cdot w_{i}$ for all $i \in N$,

(2) for all $i \in N$, there does not exist $x_{i} \in \mathbb{R}_{+}^{L}$ such that

(2.a) $x_{i} P_{i} x_{i}^{*}$

(2.b) $p^{*} \cdot x_{i} \leqq p^{*} \cdot w_{i}$;

(2.c) $x_{i} \leqq \sum_{j=1}^{n} w_{j}$

(3) $\sum_{j=1}^{n} x_{j} \leqq \sum_{j=1}^{n} w_{j}$

Denote by $W_{c}(e)$ the set of all such allocations.

Remark 1. From the above definition, we can see that every ordinary Walrasian allocation (competitive equilibrium allocation) is a constrained Walrasian allocation and that a constrained Walrasian allocation differs from a Walrasian allocation only in the way that each agent maximizes his preferences not only subject to his budget constraint but also subject to total endowments available to the economy.

Remark 2. Note that even though Walrasian equilibria do not exist (so that the competitive mechanism fails) for some non-classical economic environments, the constrained Walrasian equilibria may still exist. The following example shows that the set of constrained Walrasian allocations can be nonempty but the set of Walrasian allocations is empty for some economies in which preferences of agents are discontinuous and non-convex.

Example 1. Consider an exchange economy $e$ with two goods and two agents whose endowments are given by $w_{1}=w_{2}=(1,1)$. The utility function of agent 1 is given by $u_{1}\left(x_{11}, x_{12}\right)=x_{11}$ when $x_{11} \neq 2$ and $u_{1}\left(x_{11}, x_{12}\right)=0$ when $x_{11}=2$. The utility function of agent 2 is given by $u_{2}\left(x_{21}, x_{22}\right)=x_{22}$. One can see that this economy does not have a competitive equilibrium but the allocation $x=\left(x_{1}, x_{2}\right)$ with $x_{1}=(1,0), x_{2}=(1,2)$ is a constrained Walrasian allocation with associated price vector $p^{*}=(1,0)$.

An allocation $x$ is Pareto-efficient with respect to strict preference profile $P=\left(P_{1}, \ldots, P_{n}\right)$ if it is feasible (i.e., $x \in \mathbb{R}_{+}^{n L}$ and $\left.\sum_{j=1}^{n} x_{j} \leqq \sum_{j=1}^{n} w_{j}\right)$ and there does not exist another feasible allocation $x^{\prime}$ such that $x_{i}^{\prime} P_{i} x_{i}$ for all $i \in N$.

An allocation $x$ is individually rational with respect to $P$ if $\neg w_{i} P_{i} x_{i}$ for all $i \in N^{7}$.

\footnotetext{
7 This definition coincides with the conventional definition when $P_{l}$ is the asymmetric part of a reflexive, transitive, and total preference $R_{i}$.
} 
It can be easily shown that every constrained Walrasian allocation is Paretoefficient and individually rational ${ }^{8}$.

\subsection{Mechanism}

Let $F$ be a social choice rule, i.e., a correspondence from $E$ to the set $Z$ of resource allocations. In the rest of the paper, we will use the constrained Walrasian correspondence as the social choice rule.

Let $M_{i}$ denote the $i$-th message (strategy) domain. Its element are written as $m_{i}$ and called messages. Let $M=\prod_{i=1}^{n} M_{i}$ denote the message (strategy) space. Let $X: M \rightarrow Z$ denote the outcome function, or more explicitly, $X_{i}(m)$ is the $i$-th agent's outcome at $m$. A mechanism consists of $\langle M, X\rangle$ defined on $E$. A message $m^{*}=\left(m_{1}^{*}, \ldots, m_{n}^{*}\right) \in M$ is a Nash equilibrium (NE) of the mechanism $\langle M, X\rangle$ for an economy $e$ if for any $i \in N$ and for all $m_{i} \in M_{i}$,

$$
\neg X_{i}\left(m^{*} / m_{i}, i\right) P_{i} X_{i}\left(m^{*}\right) \text {, }
$$

where $\left(m^{*} / m_{i}, i\right)=\left(m_{1}^{*}, \ldots, m_{i-1}^{*}, m_{i}, m_{i+1}^{*}, \ldots, m_{n}^{*}\right)$. The outcome $X\left(m^{*}\right)$ is then called a Nash (equilibrium) allocation. Denote by $V_{M, X}(e)$ the set of all such Nash equilibria and by $N_{M, X}(e)$ the set of all such Nash (equilibrium) allocations.

Remark 3. The constrained Walrasian allocations and Nash allocations without ordered preferences which are defined above may not be the same as the usual ones. So Hurwicz [12] called Nash equilibrium defined by (1) as generalized Nash equilibrium. However, when preferences are transitive and total, Nash equilibrium and constrained Walrasian allocations defined above reduce to the conventional ones.

A mechanism $\langle M, X\rangle$ fully Nash-implements the social choice correspondence $F$ on $E$ if, for all $e \in E, N_{M_{0} X}(e)=F(e)$.

Remark 4. Note that the above definition which was due to Hurwicz [8, p 219] allows the social choice correspondence $W_{c}$ and the set Nash equilibria to be empty for the main purpose of this paper is to study the equivalence of the constrained Walrasian correspondence and the set of Nash equilibrium allocations under the minimal possible assumptions ${ }^{9}$. A stronger definition of full Nashimplementation used in the literature is that not only $N_{M, X}(e)=F(e)$ but also $N_{M, X}(e) \neq \emptyset$ for all $e \in E$. Thus, if we restrict the domain of $W_{c}$ to the one on which $W_{c}$ is nonempty-valued, our results, to be presented below, will be equivalent for both definitions and show that no assumptions on preferences are needed for feasible and continuous implementation of the constrained Walrasian correspondence for the class of economies on which it is nonempty-valued.

A mechanism $\langle M, X\rangle$ is individually feasible if $X(m) \in \mathbb{R}_{++}^{n L}$ for all $m \in M$.

8 For weak preferences, Thomson [30] showed that a constrained Walrasian allocation may not be (regular) Pareto-efficient (i.e., there is no way of making everyone at least well off and one person better off) even if preferences satisfy local non-satiation. However, when preferences satisfy strict monotonicity, it is (regular) Pareto-efficient by Theorem 2.iv of Tian [32].

9 Of course, if we impose more assumptions on preferences, by using the results such as in Mas-Colell [18], Shafer and Sonnenschein [28], Tian [35], and Tian and Zhou [39], we can prove the existence of constrained Walrasian equilibria. 
reto-

surce

$\mathrm{cor}-$

ritten

pace.

e $i$-th

ssage

$>$ for

then

such

tions.

thout

usual

Nash

uilib-

nven-

dence

2 219]

to be

of the

lloca-

Nash-

$t$ also

ne on

zquiv-

eeded

n cor-

sn may

off and

erences

$h$ as in

we can

A mechanism $\langle M, X\rangle$ is weakly balanced if for all $m \in M$

$$
\sum_{j=1}^{n} X_{j}(m) \leqq \sum_{j=1}^{n} w_{j} .
$$

A mechanism $\langle M, X\rangle$ is balanced if (2) holds with equality for all $m \in M$.

A mechanism $\langle M, X\rangle$ is completely feasible (or feasible) if it is individually feasible and balanced (or weakly balanced).

Sometimes we say that an outcome function is individually feasible, balanced, or continuous if the mechanism is individually feasible, balanced, or continuous.

\section{Completely feasible and continuous implementation}

In this Section, we present a simple mechanism which is completely feasible and continuous and fully Nash-implements the constrained Walrasian correspondence for a class of economies $\tilde{E} \subset E$ satisfying monotonicity of preferences. In the following section, we will consider feasible and continuous implementation on $E$ without assuming monotonicity of preferences.

The mechanism can be simply described as follows. The designer first asks each agent to report proposed prices for other agents and proposed contributions that the agent is willing to give to each person including himself. Based on this information, the designer determines prices of goods according to agent's proposed prices. Then a completely feasible choice correspondence $B$ is defined in such a way that for all $m \in M$, allocations in $B(m)$ are completely feasible and satisfy the budget constraints with equality for all agents. The allocation outcome $X(m)$ will be chosen from the completely feasible set $B(m)$ so that it is the closest to the sum of the contributions that each agent is willing to pay.

We now turn to the formal construction of the mechanism. For each $i \in N$, let the message domain of agent $i$ be of the form ${ }^{10}$

$$
M_{i}=\mathbb{R}_{++}^{L} \times \mathbb{R}^{n L} \text {. }
$$

A generic element of $M_{i}$ is $m_{i}=\left(p_{i}, x_{i 1}, \ldots, x_{i n}\right)$, where $p_{i}$ is interpreted as the price vector proposed by agent $i$ for other agents and $x_{i j}$ is interpreted as the contribution that agent $i$ is willing to make to agent $j$ (a negative $x_{i j}$ means agent $i$ wants to get $-x_{i j}$ amount of goods from agent $j$ ).

Define the price vector $p: M \rightarrow \mathbb{R}_{+}^{L}+$ by

$$
p(m)=\left\{\begin{array}{ll}
\sum_{i=1}^{n} \frac{a_{i}}{a} p_{i} & \text { if } a>0 \\
\sum_{i=1}^{n} \frac{1}{n} p_{i} & \text { if } a=0
\end{array},\right.
$$

where $a_{i}=\sum_{j, k \neq i}\left\|p_{j}-p_{k}\right\|$, and $a=\sum_{i=1}^{n} a_{i}$, and $\|\cdot\|$ is the Euclidian norm. Then $p(m)$ is continuous on $M^{11}$.

in The dimension of the message domain can be reduced by one by normalizing the price of some good to one so that $M_{i}=\mathbb{R}_{++}^{L-1} \times \mathbb{R}^{n L}$.

" $p(m)$ is clearly continuous at $m$ with $a>0$. When $a=0, p_{1}=\ldots=p_{n}=p$ and thus, for any $\varepsilon>0,\left\|p\left(m^{\prime}\right)-p(m)\right\|=\left\|\sum_{i=1}^{n} \frac{a_{i}^{\prime}}{a^{\prime}} p_{i}^{\prime}-p\right\|=\left\|\sum_{i=1}^{n} \frac{a_{i}^{\prime}}{a^{\prime}}\left(p_{i}^{\prime}-p\right)\right\| \leqq \sum_{i=1}^{n}\left\|p_{i}^{\prime}-p\right\|<\varepsilon$ as long as $p_{i}^{\prime}$ is sufficiently close to $p$ for all $i \in N$. Hence, $p(m)$ is also continuous at $m$ with $a=0$. 
Note that though $p(\cdot)$ is a function of proposed prices anly. for sumpli we can write $p($.$) as a function of m$ without hass of geneablery

Detine a completely feasible currespondence $B: M \rightarrow \rightarrow R^{2}{ }_{4}$ by

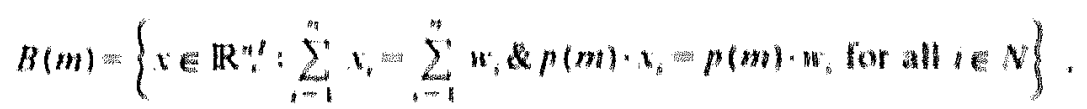

which is a continuous correspondence with nonernpty. compact. and con values (ct. "Tian [3]]).

Let $x_{i}=\sum_{i=1}^{n} x_{i}$, which is the sum of contributions that agcots are willin

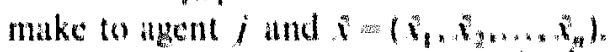

The oufcome function $X: M \rightarrow \mathbb{R}^{m i t}$ is taven by

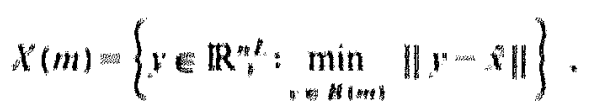

which is the closet to : "Then $X$ is singlevalued and contmuous on $M^{10 *}$. A since $X(m)$ es $\mathbb{R}_{\neq}^{m t}$ and

$$
\sum_{i=1}^{n} X_{x}(m) \sum_{i=1}^{n} n_{i}
$$

for all $m \in M$, the mechanism is completely leasible and contmuou.

Resturk 5. Note that the above mechanism is different from the one givet Postlewaite and Wettstein [25] in two ways: 11) Our mechanism is balar while their mechanism is merely weakly balanced. (t) Fach movidual in mechanism announces amounts to a whole allocation rather than jest his 1 demand. This enables us to get continuous implementation wathut assun continuous preferences while continuly of preferences is a critical assump for their mechanism.

Now we show equivalence between Nash equilibrim allowations and strained Walrasian allocations. Proposilion I shows that every Nash equilibr allocation is a constrained Walrasian allocation. Proposition 3 proves that e constrained Walrasian allocation is a Nash equilibrium allocation.

Proposition 1. If the mechanism $\langle M, X\rangle$ defined above hax of Nosht equilibrium

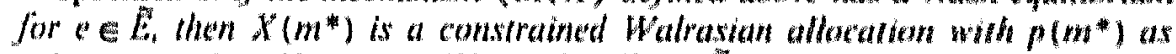

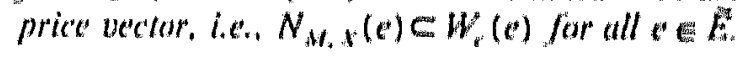

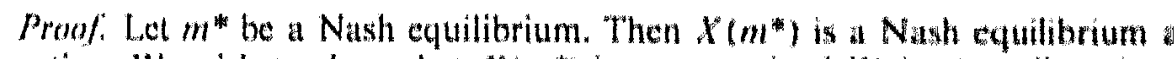
cation. We wish to show that $X\left(m^{*}\right)$ is a constrained Watrasian allocation. the defintion of the mecharism, we know that $p\left(m^{*}\right)$ e $\mathbb{R}^{t}, \ldots\left(m *^{*}\right)$ e $\sum_{i=1}^{n} X_{i}\left(m^{*}\right)=\sum_{i=1}^{n} w_{1}$, and $p\left(m^{*}\right) \cdot X_{i}\left(m^{*}\right)=p\left(m^{*}\right) \cdot w_{k}$ for all te $N$. Sa we need to show that each individual is naximizing his/her preferences. Supp by way of contradiction, that for some agent, say, agent 1 , there exists st

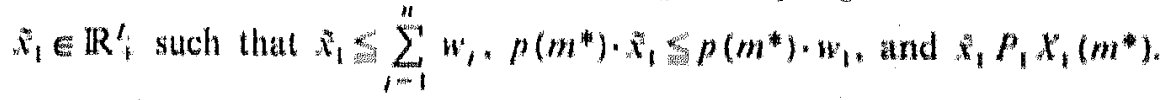

\footnotetext{
17his is bectuse $X$ is an upper semincontinuous correspondence by Herget Maximum The
} (see Debreu $[3, p$ 19]) and single valued (wee Mascolell $[19,028] 1$. 
T)

aity,

Wex

10

146.

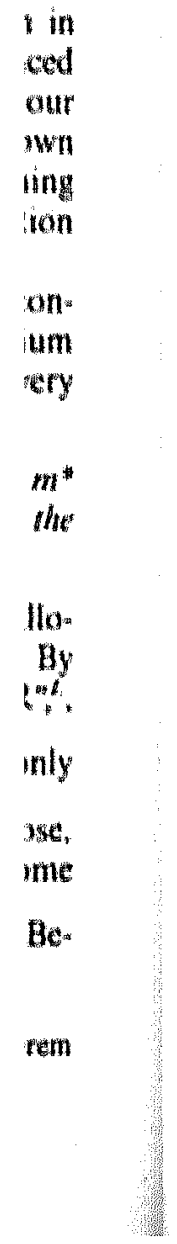

cause of monotonicity of preferences, it will be enough to confine ourselves to the case of $p\left(m^{*}\right) \cdot s_{1}^{*} p\left(m^{*}\right) \cdot w_{1}$ :

Define $\tilde{x}_{v}(i=2, \ldots, n)$ as follows:

$$
x_{i}=\frac{p\left(m^{*}\right) \cdot w_{i}}{\sum_{i m b}^{n} p\left(m^{*}\right) \cdot w_{i}}\left[\sum_{i=1}^{n} w_{i}-\sum_{j=1}^{1} x_{i}\right] \text {. }
$$

Since $\tilde{x}_{1} \sum_{n=1}^{n} w_{n}$, it can be easily verified, by reduction, that

$$
\sum_{i=1}^{n} w_{1}-\sum_{i=1}^{1} x_{i}^{1} \geq 0
$$

for $i=2, \ldots, n$ and thus $x_{k} \in \mathbb{R}_{i}^{t_{i}}$ and

$$
p\left(m^{*}\right) \cdot \tilde{r}_{k}=p\left(m^{*}\right) \cdot w_{k}
$$

for all $k=2, \ldots, n$. Also, by letting $i=n$ in (8), we have

$$
\sum_{j=1}^{n} x_{j}, \sum_{j=1} w_{j} \text {. }
$$

Now suppose that agent I chooses $x_{1},=x_{1},-\sum_{k \neq 1} x_{h}^{*}$ for all $j \in N$ and keeps $p_{i}^{*}$ unchanged, i.e., $m_{1}=\left(p_{1}^{*}, x_{11}, \ldots, x_{1 n}\right)$. Then $x^{x}\left(x_{1}^{*}, x_{2}, \ldots, x_{n}\right) \in B\left(m^{*} / m_{1}, 1\right)$ and $x_{1}=x_{1},+\sum_{k \neq 1} x_{k,}^{*}$ for all $j \in N$. Hence, we have $X_{1}\left(m^{*} / m_{1}, 1\right)=x_{1}$. Therefore, from $\tilde{x}_{1} P_{1} X_{1}\left(m^{*}\right)$, we have $X_{1}\left(m^{*} / m_{1}, 1\right) P_{1} X_{1}\left(m^{*}\right)$. This contradicts the fact that $m^{*}$ is a Nash equilibrium. So $X\left(m^{*}\right)$ is a constrained Walrasian allocation. Q.E.D.

Proposition 2. If $x^{*}=\left(x_{1}^{*}, x_{2}^{*}, \ldots, x_{n}^{*}\right)$ is a constrained Walrasian allocation with a

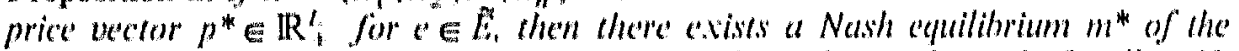
merhanism $\langle M, X\rangle$ defined above such that $X,\left(m^{*}\right), x_{i}^{*}, p\left(m^{*}\right)$ was $p^{*}$, for all $i \in N$,

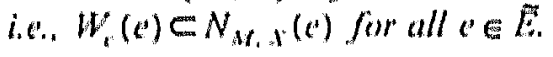

Prool. Since preferences satisfy the monotonicity condition and $x^{*}$ is a constrained Walrasian allocation, we must have $p^{*} \in \mathbb{R}_{+}^{t}, \sum_{j=1}^{n} x_{j}^{*}=\sum_{j=1}^{n} w_{j}$ and $p^{*} \cdot x_{i}^{*} p^{*} \cdot w_{\text {, for }} i \in N$. Now for each $i \in N$, let $m_{i}^{*}=\left(p^{*}, x_{i}^{*}, \ldots . x_{i n}^{*}\right)$, where

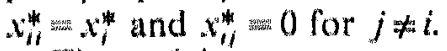

Then $x^{*}$ is an outcome with $p^{*}$ as a price vector, i.e., $X_{1}\left(m^{*}\right)=x_{i}^{*}$ for all $i \in N$, and $p\left(m^{*}\right) p^{*}$. We show that $m^{*}$ yields this allocation ats a Nash allocation. In fact, agent $i$ cannot change $p\left(m^{*}\right)$ by changing his proposed price since changing $p_{i}$ yields $a>0$ and $a_{i}=0$ so that the new $p_{i}$ cannot change $p\left(m^{*}\right)$ (i.e., $p\left(m^{*} / m_{t}, i\right)=p\left(m^{*}\right)$ for all $\left.m_{i} \in M_{i}\right)$. Announcing a different message $m_{i}$ by agent $i$ may yield an allocation $X\left(m^{*} / m_{i}, i\right)$ such that $X_{r}\left(m^{*} / m_{l}, i\right) \in \mathbb{R}_{+}^{L_{+}}$ and

$$
p\left(m^{*}\right) \cdot X_{i}\left(m^{*} / m_{i}, i\right)=p\left(m^{*}\right) \cdot w_{1} .
$$

Now suppose, by way of contradiction, that $m^{*}$ is not a Nash equilibrium. Then 


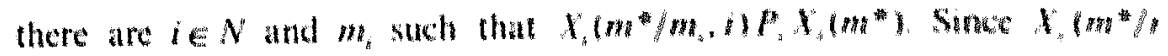

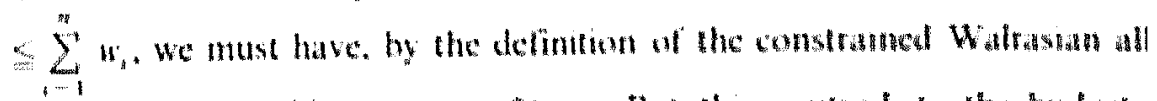

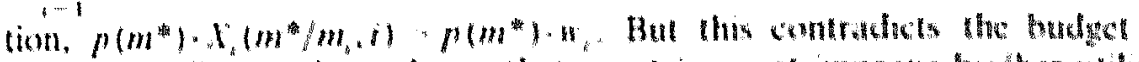

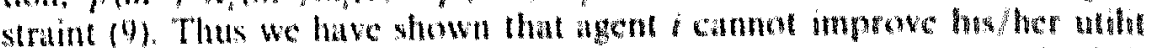
changing his/her own message while the athers ${ }^{*}$ messiges remann hed fo ie $N$. Hence $x$ is a Nash allocution. Q.E.D.

Remurk o. It may be remarked that when we prove that every Nath eapentith allocation is a constraind Walrasian allocation on Proposoten l. We do require that all participants" price messiges be the same at it Noblo cquablur and thus even at a Nash equilibrium a participant can change the ruteome changing his/het awn price messages. However. when we prove that every

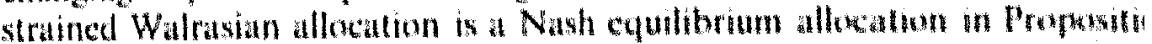
the Nash equilibrium is chosen in a way that all participants" prese unessage the same so that any participant camnot chatuge the prevaling prece vecte changing his/her own nessages (so that every particinant takes proes as gh

Summariging the above discussions, we have the following theorem.

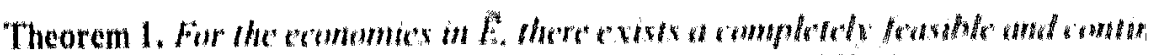

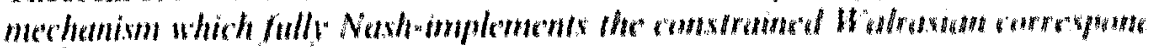
on $E_{\text {s. }}$.

Since the constrained Walrasian allocations are Paretoweflecient and and ually rational, we then have the following corollary,

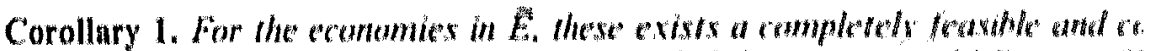

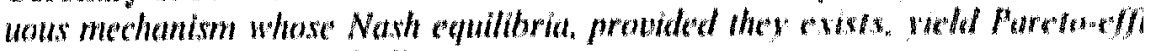
and individually rational allocations.

Remark 7. Note that the monotonicity assumption we only moned in this se: cannot be dispensed with for balanced implementation. Indeced, without assumption, the constrained Walrasian allowations can be weakly batanced case of free-disposal), and consequently cannot be attaned with the balat mechanisms.

\section{Feasible and continuous implementation}

In the previous section, we needed to assume that preferenes of agent monotone increasing in order to obtain a completely feasible and contic mechanism. This assumption is indispensable if one wants to a voud freectise This assumption, however, can be dropped if we allow for free disposal and want to have a mechanism which is merely feasible (individually feasibite weakly balanced) and continuous and Nashmimplements the constrained rasian correspondence. This section gives such a mechanism which is very si to the presented in the previous section. We briefly describe it as follows.

The message space is given by

$$
M_{1}, \mathbb{R}_{+}^{l} \mathbb{x}^{\prime \prime \prime} \mathbb{R}^{\prime \prime} \text {. }
$$


The price vector is the same as before and the completely feasible correspondence is modified to the feasible correspondence $B^{\prime}: M \rightarrow \rightarrow \mathbb{R}_{+}^{n L}$ defined by

$$
B^{\prime}(m)=\left\{x \in \mathbb{R}_{+}^{n L}: \sum_{i=1}^{n} x_{i} \leqq \sum_{i=1}^{n} w_{i} \& p(m) \cdot x_{i} \leqq p(m) \cdot w_{i} \text { for all } i \in N\right\},
$$

which is a continuous correspondence with nonempty, compact, and convex values. The outcome function for goods is similarly defined, i.e., $X(m)$ will be chosen from the feasible set $B^{\prime}(m)$ so that it is the closest to the sum of the contributions that each agent is willing to pay. Thus the mechanism is feasible and continuous.

The proof of equivalence of Nash allocations of the modified mechanism and the constrained Walrasian correspondence remains the same except for replacing "equality" by "inequality" and defining $\tilde{x}_{i}$ in (8) by $\tilde{x}_{i}=0$ for $i=2, \ldots, n$.

Thus we have the following result.

Theorem 2. For the class of economies $E$, there exists a feasible and continuous mechanism which fully Nash-implements the constrained Walrasian correspondence.

Similarly, we have

Corollary 2. For the class of economies $E$, there exists a feasible and continuous mechanism whose Nash equilibria, provided they exist, yield Paretoefficient and individually rational allocations.

\section{Concluding remarks}

In Sect. 3 we gave a simple mechanism which is completely feasible and continuous and fully Nash-implements the constrained Walrasian correspondence for economies without total, transitive, continuous, and convex preferences. We then show in Sect. 4 that if the society allows for free-disposal, monotonicity of preferences can be dropped and gives a mechanism which is feasible and continuous and implements the correspondence. Thus no assumption on preferences are needed for feasible and continuous implementation, and therefore any constrained Walrasian allocation can be attained by our mechanism. In the following, we want to mention some possible extensions of our mechanism.

First, in the mechanisms presented above, the initial endowments are assumed to be known to the designer. However, the mechanism in Sect. 3 can be extended to the case where the initial endowments are private information. Such a mechanism can be obtained by modifying the message space to

$$
M_{i}=\left(0, w_{i}\right] \times \mathbb{R}_{+}^{L}+\times \mathbb{R}^{n L} .
$$

Here $w_{i}$ is assumed to be a strictly positive vector. A generic element of $M_{i}$ is $\left(v_{i}, p_{i}, x_{i 1}, \ldots, x_{i n}\right)$, where $v_{i}$ denotes a profession of agent $i$ 's endowment, the inequality $0<v_{i}<w_{i}$ means that the agent can understate but not overstate his own endowment, the claimed endowment $v_{i}$ (like the true endowment $w_{i}$ ) must be positive. Interpretations of other components are the same as before. The completely feasible correspondence is modified to the feasible correspondence $B^{\prime \prime}: M \rightarrow \rightarrow \mathbb{R}_{+}^{n L}$ defined by

$$
B^{\prime \prime}(m)=\left\{x \in \mathbb{R}_{+}^{n L}: \sum_{i=1}^{n} x_{i}=\sum_{i=1}^{n} v_{i} \& p(m) \cdot x_{i}=p(m) \cdot v_{i} \text { for all } i \in N\right\},
$$


there are $i \in N$ and $m_{i}$ such that $X_{i}\left(m^{*} / m_{i}, i\right) P_{i} X_{i}\left(m^{*}\right)$. Since $X_{i}\left(m^{*} / m_{i}, i\right)$ $\leqq \sum_{i=1}^{n} w_{l}$, we must have, by the definition of the constrained Walrasian allocation, $p\left(m^{*}\right) \cdot X_{i}\left(m^{*} / m_{i}, i\right)>p\left(m^{*}\right) \cdot w_{j}$. But this contradicts the budget constraint (9). Thus we have shown that agent $i$ cannot improve his/her utility by changing his/her own message while the others' messages remain fixed for all $i \in N$. Hence $x^{*}$ is a Nash allocation. Q.E.D.

Remark 6 . It may be remarked that when we prove that every Nash equilibrium allocation is a constrained Walrasian allocation in Proposition 1, we do not require that all participants' price messages be the same at a Nash equilibrium, and thus even at a Nash equilibrium a participant can change the outcomes by changing his/her own price messages. However, when we prove that every constrained Walrasian allocation is a Nash equilibrium allocation in Proposition 2, the Nash equilibrium is chosen in a way that all participants' price messages are the same so that any participant cannot change the prevailing price vector by changing his/her own messages (so that every participant takes prices as given).

Summarizing the above discussions, we have the following theorem.

Theorem 1 . For the economies in $\tilde{E}$, there exists a completely feasible and continuous mechanism which fully Nash-implements the constrained Walrasian correspondence on $\tilde{E}$.

Since the constrained Walrasian allocations are Pareto-efficient and individually rational, we then have the following corollary.

Corollary 1. For the economies in $\widetilde{E}$, these exists a completely feasible and continuous mechanism whose Nash equilibria, provided they exists, yield Pareto-efficient and individually rational allocations.

Remark 7. Note that the monotonicity assumption we only imposed in this section cannot be dispensed with for balanced implementation. Indeed, without this assumption, the constrained Walrasian allocations can be weakly balanced (the case of free-disposal), and consequently cannot be attained with the balanced mechanisms.

\section{Feasible and continuous implementation}

In the previous section, we needed to assume that preferences of agents are monotone increasing in order to obtain a completely feasible and conticuous mechanism. This assumption is indispensable if one wants to avoid free-disposal. This assumption, however, can be dropped if we allow for free-disposal and only want to have a mechanism which is merely feasible (individually feasible and weakly balanced) and continuous and Nash-implements the constrained Walrasian correspondence. This section gives such a mechanism which is very similar to the presented in the previous section. We briefly describe it as follows.

The message space is given by

$$
M_{i}=\mathbb{R}_{+}^{L} \times \mathbb{R}^{n L} \text {. }
$$


which is a continuous correspondence with nonempty, compact, and convex values. The outcome $X(m)$ will be chosen from the feasible set $B^{\prime \prime}(m)$ so that it is the closest to the sum of the contributions that each agent is willing to pay. Thus, the mechanisms is feasible and continuous.

Under the assumption of monotonicity of preferences, we can easily show that, at Nash equilibrium, $v_{i}^{*}=w_{i}$ for all $i \in N$. Then the proof of equivalence of Nash allocations of the modified mechanism and the constrained Walrasian correspondence is the same as in Sect. 3. Thus, the mechanism simplifies the mechanism proposed by Postlewaite and Wettstein [25] and only monotonicity of preferences is assumed so that our mechanism works even for non-neoclassical economic environments.

Secondly, the dimension of the message space of the mechanism in this paper, even though it is finite, is higher than that of the mechanism proposed by Postlewaite and Wettstein [24]. So far we do not know whether or not there exists a completely feasible and continuous mechanism which implements the constrained Walrasian correspondence (if so - for what categories of economic environments) and has a message space of lower dimension.

Finally, though this paper only considers implementation of the constrained Walrasian correspondence by using the concept of Nash equilibrium to describe self-interested behavior of individuals, we think some of the techniques developed in the paper can be applied to implement the constrained Walrasian correspondence using other solution concepts such as those of subgame perfect equilibrium and undominated Nash equilibrium. It is well-known that the Nash equilibrium approach may have a problem in the case of multiple equilibria. Some Nash equilibria may be more believable than others. Because of this, some equilibrium concepts may need to be used. Moore and Repullo [21] and Abreu and Sen [1] use subgame perfect equilibrium as the solution concept and gave conditions for subgame perfect implementation of social choice correspondences. Palfrey and Srivastava [23] use undominated Nash equilibrium as the solution concept, This concept, like subgame perfect equilibrium, is a refinement of Nash equilibrium. For our mechanisms, however, the multiple equilibrium problem may not be a serious problem even though these mechanisms have many Nash equilibria for each constrained Walrasian equilibrium. This is because these Nash equilibria correspond to only one outcome when constrained Walrasian equilibrium is unique and thus there is no strong reason to believe that a Nash equilibrium is preferred to others.

\section{References}

1. Abreu R, Sen A (1988) Subgame perfect implementation: a necessary and almost sufficient condition. J Econ Theory 50: 285-299

2. Bergson A (1938) A reformulation of certain aspects of welfare economics. Q J Econ 52 . 310-334

3. Debreu G (1959) Theory of value. Wiley, New York

4. Groves T, Ledyard J (1977) Optimal allocation of public goods; a solution to the free rider? problem. Econometrica 45: 783-811

5. Groves T, Ledyard J (1987) Incentive compatibility since 1972. In. Groves T, Radner R, Reiter S (eds) Information, incentive, and economic mechanisms. University of Minnesota Press, Minneapolis, MN

6. Hurwicz L (1960) Optimality and informational efficiency in resource allocation processes 
34. TianG (1990) Completely feasible and continuous Nash-implementation of the Lindahl correspondence with a message space of minimal dimension. J Econ Theory 51:443-452

35. Tian G (1991 a) Fixed points theorems for mappings with non-compact and non-convex domains. J Math Anal Appl 158: 161-167

36. Tian G (1991b) Implementation of Lindah! allocations with nontotal-nontransitive preferences. J Publ Econ 46:247-259

37. Tian G (1992) Generalizations of the FKKM theorem and Ky-Fan minimax inequality. with applications to maximal elements, price equilibrium, and complementarity. J Math Anal Appl (forthcoming papers)

38. Tian G, Li Q (1991) Completely feasible and continuous implementation of the Lindah correspondence with any number of goods. Math Soc Sci 21:67-79

39. Tian G, Zhou, J (1991) Quasi-variational inequalities with non-compact sets. J Math Anal Appl 160:583-595

40. Walker (1981) A simple incentive compatible scheme for attaining Lindahl allocations. Econometrica $49: 65-71$

\section{On the transfer and advantageous reallos} paradoxes*

\section{Fillid Rao}

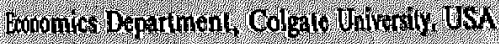

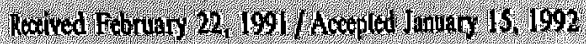

Abstract It is well known that the transfer and advantage doxes cannot occur at a Walrasian stable equitibrium in a In an innivential recent paper Chithilinisky provided an ex: faradox in the context of a globally Wilrasian stable three evident, though, that the paradoxes depend on the undettyi erences and nel export posifions of the economy. This pape generalizes the transfer and adrantageous reallocation parad saffictent conditions on the underfying dala of a globally Wa day for the occurence of each of these pandoxes are establ of the third agent in generating these paradoxes is clarified.

\section{Tlinirodiction}

litidear that in a world in which prites do not change, a tyrevipient sendowment will raise is velfare (and lower $t$

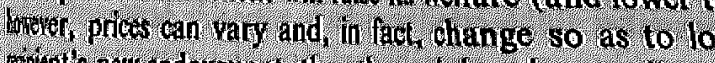
expients new codowment, then the recipient is actually $m$ Mthis is a form of the transfer pardo $x$ ?

lithe gift redices the wellare of both the recipient and 6ill as the weak transfer paradox weak beeause only fitution is paradoxicaly. When the gift benefits the donor infl le terned the strong transler paradox.

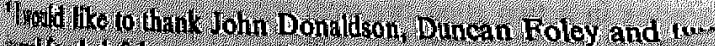

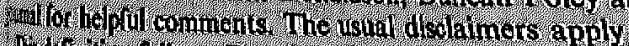

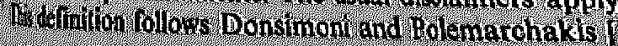


and conver 赫) what it Why 10 py.

canty show itivalence of illusulan cor. 3the mech stonicty of neoklassical

this paper, ad by posis Mhere exists s the con momic en.

onstratined to describe developed worrespon. quilibrium quilibrium ame Nash juilibrium ud Sen [1] litions for Ilfrey and eepl. This uilibrium. not be a libria for wquilibria ibrium is ibrium is

suflicient

Econ 52:

free rider'

adner R, linnesota

trocetses.
In: Arrow KJ, Karlin S, Suppes P (eds) Mathematical methods in the social sciences. Stanford University Press, Stanford

7. Hurwicz $L$ (1972) On informationally decentralized systems. In: Radner R, McGuire CB (eds) Decision and organization, p 297-336, (volume in honor of $J$ Marschak). Elsevier, North-Holland, Amsterdam

8. Hurwicz L. (1979a) Outcome functions yiclding Walrasian and Lindahl allocations at Nash equilibrium points. Rev Econ Stud 46:217-225 9. Hurwiez L (1979 b) On allocations attainable through Nash equilibria. J Econ Theory 21 :
$149=165$

10. Hurwicz L (1985) A perspective. In: Hurwicz L, Schmeidler D, Sonnenschein H (eds) Social goals and social organization - essays in memory of Elisha Pazner, p I-16. Cambridge
University Press, Cambridge

11. Hurwice $L$ (1986a) Incentive aspects of decentralization. In: Arrow KJ, Intriligator MD (eds) Handbook of mathematical economics, vol III, p 1441-1482. Elsevier, North-Holland,
Amsterdam

12. Hurwicz L. (1986b) On the implementation of social choice rules in irrational societies. In: Heller WP, Ross RM, Starrett DA (eds) Social choice and public decision making - essays in honor of Kenneth J Arrow, vol I, p 75-96. Cambridge University Press, Cambridge

13. Hurwicz $L$ (1986c) On informational decentralization and efliciency in resource allocation mechanism. In: Reiter S (ed) Studies in mathematical economies. Mathematical Association of Ameriea

14. Hurwicz L, Maskin E, Postlewaite A (1984) Fcasbile implementation of social choice correspondences by Nash equilibria. University of Minnesota (mimeo) 15. Kim T, Richter MK (1986) Nontransitivennontotal consumer theory. J Econ Theory 38:
324-363

16. Kwan KY, Nakamura $S$ (1987) On Nash implementation of the Walrasian or Lindahl correspondence in the two-agent cconomy. Discussion Paper \#243, University of Minnesota

17. Lange O (1942) The foundation of welfare economics. Econometrica 10:215-228

18. Mas-Colell A (1974) An equilibrium existence theorem without complete or transitive preferences. J Math Econ 1:237-246

19. Mas-Colell A (1985) Theory of general economic equilibrium - a differentiable approach. Cambridge University Press, Cambridge

20. Maskin E (1977) Nash equilibrium and welfare optimality. M.L.T., October (mimeo)

21. Moore J, Repullo R (1988) Subgame game perfect implementation. Econometrica 56: $1191 \ldots 1220$

22. Mosteller Fi, Nogee P (1951) An experimental measure of utility. J Polit Econ 59: 371-404

23. Palfrey T, Srivastava $S$ (1991) Nash implementation using undominated strategy. Econometrica $59: 479-502$

24. Postlewaite A, Wettstein D (1983) Implementing constrained Walrasian equilibria continuously. CARESS Discussion Paper 83-24, University of Pennsylvania, Philadelphia

25. Postlewate A, Wettstein D (1989) Continuous and feasible implementation. Rev Econ Stud $56: 603 m 611$

26. Schmeidler D (1969) Competitive equilibrium in markets with a continuum of traders and incomplete preferences. Econometrica 37: 578-585

27. Schmeidler D (1980) Walrasian analysis via strategic outcome functions. Econometrica 48: 1585-1593

28. Shafer W, Sonnenschein H (1975) Equilibrium in abstract economies without ordered preferences. J Math Econ 2: 345-348

29. Sonnenschein H (1971) Demand theory without transitive preferences, with application to the theory of competitive equilibrium. In: Chipman, IS, Hurwicz L, Richter MK, Sonnenschein H (eds) Preferences, utility, and demand. Harcourt Brace Jovanovich, New York

30. Thomson W (1985) Manipulation and implementation in economics. University of Rochester, unpublished book

31. Ttan $\mathbf{G}(1987)$ Nash-implementation of social choice correspondences by completely feasible continuous outcome functions. Ph. D. Dissertation, University of Minnesota

32. Tian $G$ (1988) On the constrained Walrasian and Lindahl correspondences. Econ Lett 26: $299-303$

33. Tian $G$ (1989) Implementation of the Lindahl correspondence by a single-valued, feasible, and continuous mechanism. Rev Econ Stud 56:613-621 